\title{
SULFUR-MODIFIED COMPOSITES FOR ENHANCEMENT OF BUILDING FOUNDATIONS
}

\author{
S.Y. Efremova ${ }^{1, *}$, M.I. Panfilova ${ }^{2}$, N.I. Zubrev ${ }^{3}$, N.A. Politaeva ${ }^{4}$, and A.A Goryacheva ${ }^{1}$ \\ ${ }^{1}$ Penza State Technological University, PenzSTU \\ ${ }^{2}$ Moscow State University of Civil Engineering \\ ${ }^{3}$ Russian University of Transport (MIIT) \\ ${ }^{4}$ Peter the Great St. Petersburg Polytechnic University
}

\begin{abstract}
This paper considers the issues of improving the strength characteristics of foundations by injecting specially selected composite mortars into soils. The properties of injection mortars used in seismic hazardous areas are improved using various additives consisting of various wastes. The article explores the possibility of using a composite mortar modified with sulfur, which is waste from oil refining. The influence of its addition on the strength characteristics of composite materials is studied. The optimal content of sulfur addition was determined, which makes it possible to increase the strength of building mixtures by $20-30 \%$. The possibility to use a sulfur- modified composite mortar to strengthen an artificial foundation for reducing the seismicity of the construction site was proven.
\end{abstract}

\section{Introduction}

Earthquake-resistant construction is used in areas prone to earthquakes, taking into account the influence of seismic forces on buildings and structures. The likelihood of seismic impact on buildings and structures is determined by the physicochemical and geomorphological properties of soils. One of the most significant aspects of ensuring the seismic resistance of designed and operated buildings and structures is the antiseismic increase in the bearing capacity of soil foundations [1,2].

Strengthening of soils and increasing the stability of building foundations is performed by injecting composite mortars based on various materials [3-8]. For this purpose, holes with a diameter of $2-4 \mathrm{~cm}$ are drilled into the soil around the foundation with a step of $0.5-1$ $\mathrm{m}$ and an injector is introduced through which a fixing composite mortar is injected under pressure. Typically, the massif is reinforced within a radius of $0.6-1.2 \mathrm{~m}$ around the injector to provide a continuous massif of reinforced soil under the foundation (Fig. 1).

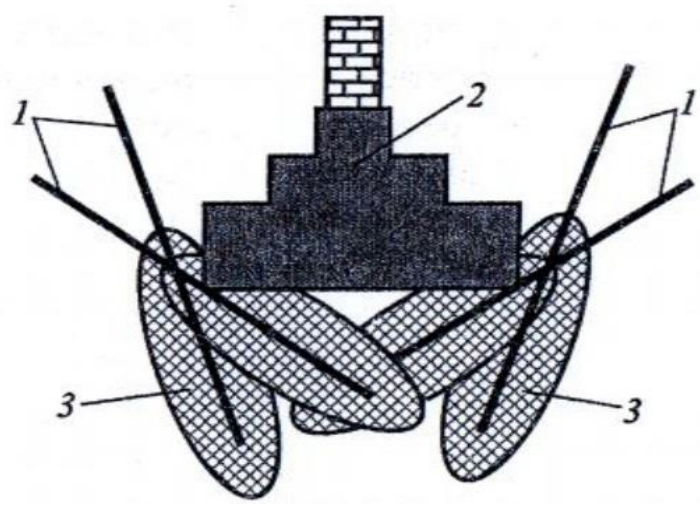

Fig. 1. Scheme for silicatization of base under the foundation: 1 - injector; 2 - foundation; 3 - strengthened zone.

Modification of the properties of an artificial foundation by injecting a composite mortar can result in reduced influence of seismicity on the stability of structures. This change is achieved by the strengthened structure and soundness of the cement stone which results in increased resistance to various deformations.

In composite injection mortars, various additives to the main component - cement are used that can accelerate structure formation and reduce the cement consumption $[9,10]$. These additives include various production wastes, in particular, industrial sulfur formed during the refining of petroleum products [11-13]. Waste in huge quantities accumulates on the territory of enterprises, and in dry form sulfur can produce dust and spread over long distances. Highly dispersed sulfur dust particles enter the nearby residential areas and cause

\footnotetext{
* Corresponding author: $\underline{\text { s sharkova } @ \text { mail.ru }}$
} 
environmental pollution. Another negative factor of the presence of sulfur particles in the environment is the formation of harmful compounds such as sulfur dioxide and hydrogen sulfide. When sulfur dioxide interacts with water droplets in the air, acid rain may occur.

The main direction of environmental policy is the involvement of production waste in the economic turnover [14-22]. There are a number of reasonable directions for the use of production waste - sulfur - in various technologies [23-27]. The most attractive is its use in the production of sulfur concrete. This material has improved characteristics, i.e. high strength, water permeability, chemical resistance, and frost resistance. Its advantage over conventional concrete is high rate of structure formation.

There are two main applications of sulfur in construction. These include polymer-sulfur concretes and asphalt-concrete mixtures that are used for road surfaces. The introduction of up to $20 \%$ sulfur in such composites leads to an increase in the mass workability at low ambient temperatures, and the shear stability of road surfaces. The disadvantage of the technology for producing sulfur-containing concretes is the need to use high temperatures. This is explained by the fact that when adding sulfur, it is necessary to use it in a molten state (it melts at temperatures above $120^{\circ} \mathrm{C}$ ).

It can be assumed that injection reinforcement of soils for strengthening foundations can be carried out with the addition of modified sulfur to the composite. However, in this case, it is necessary to change the technology of the additive introduction, since the composite mortars are preliminarily prepared and pumped to the place of fixation at ordinary temperature.

The aim of the study is to substantiate the possibility of using a composite mortar modified with technical sulfur to increase the stability of foundations.

\section{Materials and methods}

The following materials were used: cement of the 500 grade, bentonite of the P2T2A grade, technical sulfur and liquid glass. A composite mortar with W/C 2:1 was prepared by mixing bentonite with water and sulfur additions from 0.09 to $3.00 \%$ to the weight of cement, after which cement and liquid glass were added.

To determine the mixture strength, samples were prepared, which were removed from the molds in a day. Before testing, they were stored in a room with a temperature of $(20 \pm 3){ }^{\circ} \mathrm{C}$ and a relative humidity of $(65 \pm 10) \%$. Further the samples were removed from the mold. Their strength was found by crushing the cubes at the Controls 50-C0050/CAL50 press for 28 days.

\section{Results and Discussion}

Fig. 2 shows the structure formation of a composite mortar with various sulfur additives. With an increase in the content of the modifier, the strength is increased for various regularities. So, with an additive concentration of $0.3 \%$ to the mixture volume, the strength starts to significantly increase relative to the control sample, and then acquires a tendency to a gradual decrease.

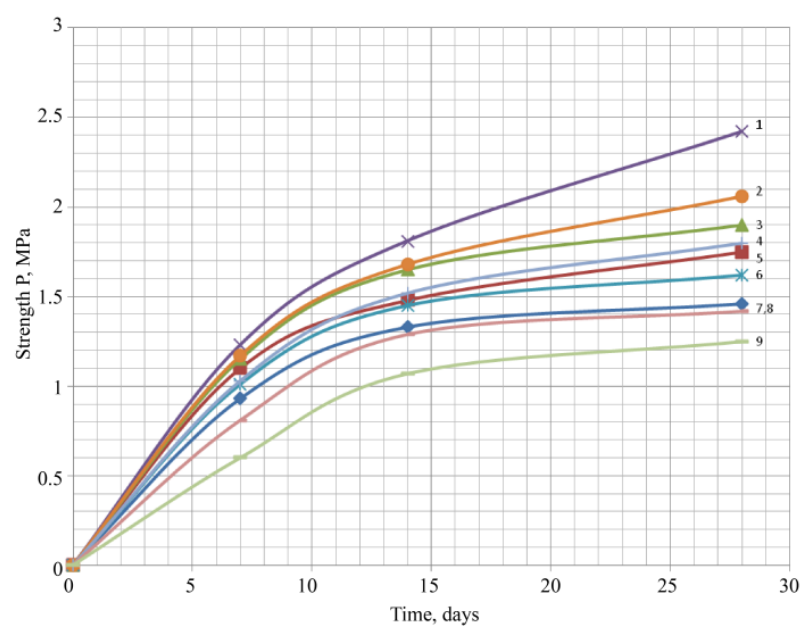

Fig. 2. Relationships between the strength of the composite mortar and storage time for various sulfur contents in cement mass, \%: 1-0.30; 2-0.60; 3-0.18; 4-0.90; 5-0.09, 6-0.36; 7-0.00; 8-1.80; 9-3.00.

Fig. 3 shows the relationship between the strength of the composite mortar and the sulfur content after 28 days of storage. It is seen that the strength of the composite mixture with the addition of $0.3 \%$ sulfur increased by about $60 \%$ as compared to the control sample.

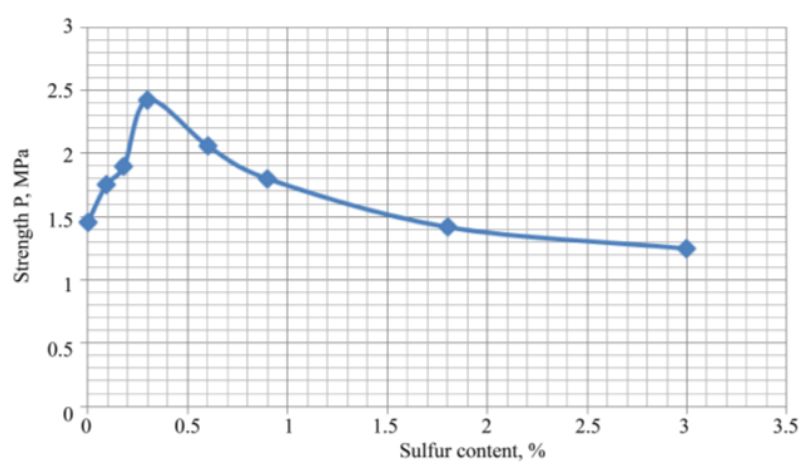

Fig. 3. Relationship between the strength of the composite mortar and the sulfur content.

Further a quantitative assessment of the structure formation of the composite system was performed. The rate of structure formation was determined by the change in the slope tangent of the strength versus time plot at different sulfur content in the mortar weight.

The analysis of the kinetics of curing, without changing the strength of the binder compositions, was carried out using the Rehbinder-Gorazdovsky device. It is a conical plastometer, which enables to evaluate the change in the plastic strength of the hardening mass over time.

During testing, for each stage of loading, the graphs of relationships between strength of the clay-cement system and the storage time were plotted for various sulfur contents. The curves obtained were used to identify linear sections, which show the deformation of the hardening mortar at a constant rate, at a given strength. For the selected linear sections, the sample 
deformation rate $\operatorname{tg} \alpha$ was determined according to the formula:

$$
\operatorname{tg} \alpha=\frac{\Delta P_{i}}{\Delta \mathrm{t}_{i}}
$$

where $\Delta P_{i}$ is the difference between the longitudinal deformations of the hardening sample at the end and the beginning of the deformation period at a constant rate at the $i$-th stage of loading, MPa;

$\Delta t_{i}$ is the duration of the period of sample hardening at a constant rate at the $i$-th stage of loading, days.

The obtained values were used to construct a plot for the relationship between the rate of the strength gain of the composite mortar $(\operatorname{tg} \alpha)$ and the sulfur relative content after 28 days of storage (Fig. 4).

Figure 4 shows that the rate of the strength gain is the highest for the composite mortar with the optimal sulfur addition. It exceeds the rate of structuring the system without the addition for almost two times. Moreover, the highest rate of structure formation of the cured composite mixture occurs during the first seven days.

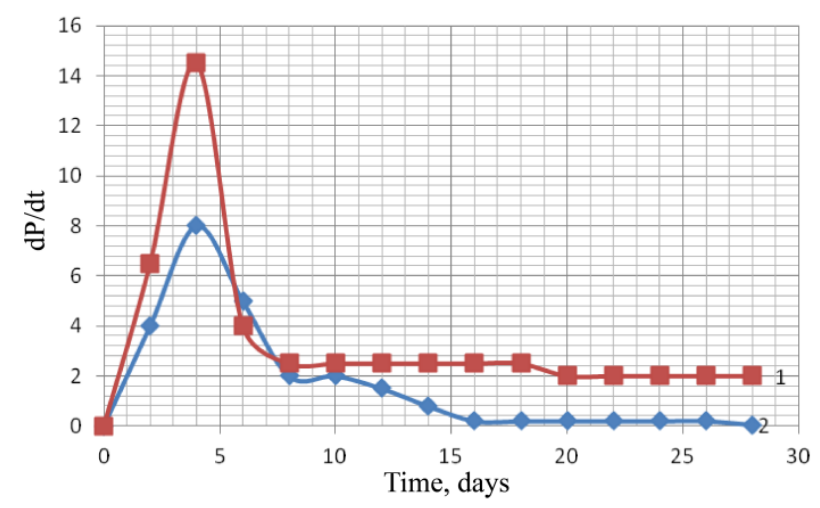

Fig. 4. Kinetics of structure formation for sulfur content, $w t \%$ : $1-0.3 \%, 2$-without additives.

The acceleration of the structure formation of the composite system can be explained by the formation of sulfur nanoformations arising from its partial dissolution in a strongly alkaline medium with $\mathrm{pH}=13$ during the preparation of the composite mortar.

Thus, the conducted studies showed that the modification of the composite mortar with sulfur under normal conditions results in abnormal changes in the structure, increases its strength and changes the kinetics of structure formation. The proposed innovations make it possible to significantly change the structural and mechanical properties of the foundation. The use of a composite mortar with the addition of waste - sulfur, depending on the depth of the existing base treatment, will solve the issue on the stability of the foundations.

\section{Conclusion}

The proposed mechanism of the structure formation process of the cement matrix of the composite mortar consists in modifying the structure of the composite mortar with sulfur with the formation of new crystallization centers in the phase solution of the cement stone. As a result of this transformation, a composite system with increased density and strength is formed, which can be used to reduce the influence of various deformations.

\section{References}

1. A.M. Uzdin, T.A. Sandovich, S.A. Al-NasserMohamad, Fundamentals of the theory of seismic resistance and earthquake-resistant construction of buildings and structures, St. Petersburg: VNIIG n.a. Vedeneev, P. 176 (1993).

2. N.G. Seregin and V.I. Zaprudnov, Improving the bearing capacity of foundations soils by cementation, Forestry Bulletin, Vol. 24, No. 5, pp. 104-108 (2020).

3. Injection chemical hardening of soils. Thermal hardening of soils: typical technological map, St. Petersburg. (2009).

4. M.N. Ibragimov, Hardening of soils by injection of cement mortars: monograph, Moscow: ASV Publishing House, 254 p. (2012).

5. E.S. Voznesenskaya, V.A. Ermolaev, A.I. Osokin, S.V. Tatarinov, Strengthening the foundations of buildings and structures by hydraulic fracturing using collar technology, Foundations, bases and soil mechanics, no. 4, pp. 19-23 (2014).

6. M.I. Bazhenov, Compositions based on finely dispersed binders for injection hardening of soils and underground parts of buildings: Thesis for the degree of Cand. of Tech. Sciences: Moscow, $127 \mathrm{p}$. (2012).

7. F. Bouchelaghem, Multi-scale modelling of the permeability evolution of fine sands during cement suspension grouting with filtration, Computers and Geotechnics, Vol. 36, Issue 6, Pp. 1058-1071 (2009)

8. M.N. Ibragimov, V.V. Semkin, A.V. Shaposhnikov, Some problems of soil hardening with microcement solutions, Academia: Architecture and Construction, no. 4, pp. 114-120 (2016).

9. B. Ayati, C. Molineux, D. Newport, C. Cheeseman, Manufacture and performance of lightweight aggregate from waste drill cuttings, Journal of cleaner production, V. 208, pp. 252-260 (2019).

10. K. Piszcz-Karas, M. Klein, J. Hupka, J. Luczak, Utilization of shale cuttings in production of lightweight aggregates, Journal of environmental management, V. 231, pp. 232-240 (2019).

11. A.A. Yusupova, R.T. Akhmetova, L.N. Shafigullin, Sulfur Composite Materials Based on Sulfide Containing Industrial Waste, Materials Engineering and Technologies for Production and Processing III Solid State Phenomena, Vol. 265, Pp. 33-38 (2017).

12. A.A. Yusupova, A.A. Bobryshev, A.A. Treschev, Development of Sulfur and Silicon Dioxide Activation Method in the Sulfur Concrete Technology, Materials Engineering and Technologies for Production and Processing IV 
Solid State Phenomena, Vol. 284, P. 1114-1118 (2018).

13. A.A. Yusupova, V.T. Erofeev, Bobryshev A.A., Activation of sulfur and opal-cristobalite-tridymite phase in sulfur concrete technology, IOP Conf. Series: Materials Science and Engineering, Vol. 463, P. 1-6 (2018).

14. S.Y. Efremova, N.I. Zubrev, M.I. Panfilova,, T.V. Matveyeva, Composite systems using ash from burning production waste, IOP Conference Series: Earth and Environmental Science, 337(1) (2019).

15. N.I. Zubrev, M.V. Ustinova, M.A. Zhuravleva, M.I. Panfilova, S.Y. Efremova, Obtaining composite solutions with the addition of ash from the burning of fuel oil, Ecology and Industry of Russia, 24(3), 10-13 (2020).

16. M.I. Panfilova, N.I. Zubrev, S.Y. Efremova, M.I. Yakhkind, Strengthening of water-saturated soils of the bases of underground structures with composite mortars modified by industrial waste, boehmite, Case Studies in Construction Materials, 12 (2020).

17. M.I. Panfilova, N.I. Zubrev, V.P. Gorbachevskii, S.Y. Efremova, The renewal of the bearing capacity of rubble masonry by the composite mortar, Journal of Physics: Conference Series, 1425(1) (2020).

18. M. Panfilova, N. Zubrev, O. Novoselova, S. Efremova, Comparative analysis of strength characteristics of grouting mortars, IOP Conference Series-Materials Science and Engineering: XXI International Scientific Conference on Advanced in Civil Engineering Construction - The Formation of Living Environment (FORM), Vol.: 365, 032038 (2018).

19. M. Panfilova, N. Zubrev, O. Novoselova, S. Efremova, Composite grouting mortar based on 3DNKM - nanocrystalline inoculant, MATEC Web of Conferences: XXVII Russian-Polish-Slovak (R-S-P) Seminar on Theoretical Foundation of Civil Engineering, Vol.04061, 196 (2018).

20. M.V. Ustinova, N.I. Zubrev, M.I. Panfilova, O.V. Novoselova, S.Y. Efremova, M.A. Zhuravleva, The preparation of composite mortars with the addition of ash from burning of used sleepers, Ecology and Industry of Russia, 22(5), 36-40 (2018).

21. S.Y. Efremova, M.I. Panfilova, N.I. Zubrev, O.V. Novoselova, Kinetics of structure formation of a composite mortar with nano-additives based on aluminium, E3S Web of Conferences, 16 (2020).

22. M. Panfilova, New construction: Zero cycle aspects, modern methods and promising materials, E3S Web of Conferences, 138, 02018 (2019).

23. K.A. Nurbaturov, N.V. Bachilova, I.M. Deux, V.S. Lysenko, T.A. Zakharova, Solution of environmental problems of Western Kazakhstan using nanotechnologies, Bulletin of the National Engineering Academy of the Republic of Kazakhstan, No. 1 (27), pp. 115-16 (2008).
24. I.A. Solomin, Industrial waste is a promising raw material for the production of building materials, Industrial and civil construction, No. 1, pp. 20-23 (2014).

25. G. Bishimbayeva, D. Zhumabayeva, Sh. Umbetova, Perspective applications of sulfur polymer composites, Industrial Technology and Engineering, V.2(19), pp.16-23 (2016).

26. J. Moon, P.D. Kalb, L. Milian, P.A. Northrup, Characterization of a sustainable sulfur polymer concrete using activated fillers, Cement and Concrete Composites, Vol. 67., P. 20-29 (2016).

27. K. Pushkarova, K. Kaverin, D. Gadayuchyk, Modified Light Concrete of High Strength, MATEC Web of Conferences, Vol. 230, 03015 (2018). 